\title{
Fatal Consequences: Obstructive Sleep Apnea in a Train Engineer
}

\author{
Mary Pat McKay, MD, MPH \\ National Transportation Safetey Board, \\ Washington, DC
}

\begin{abstract}
This special report describes the findings of the National Transportation Safety Board's investigation into the probable cause of the derailment of a Metro-North passenger train in the Bronx, New York on December 1, 2013, that resulted in 4 deaths and injuries to 59 additional persons. A key finding in the medical investigation was the engineer's post-accident diagnosis of severe, obstructive sleep apnea, and the probable cause of the accident was determined to be the result of the engineer having fallen asleep while operating the train. This accident highlights the importance of screening, evaluating, and ensuring adequate treatment of obstructive sleep apnea, particularly among patients working in positions where impairment of physical or cognitive function or sudden incapacitation may result in serious harm to the public.
\end{abstract}

Ann Fam Med 2015;13:583-586. doi: 10.1370/afm.1868.

\section{BACKGROUND}

T he National Transportation Safety Board (NTSB) is an independent federal agency charged with determining the probable cause of transportation accidents and promoting transportation safety. The NTSB is not a regulatory agency; instead, it issues safety recommendations to a variety of entities asking for actions that could prevent a similar accident from happening in the future.

\section{The Accident and Medical Investigation}

At 7:19 AM on Sunday, December 1, 2013, a Metro-North Railroad passenger train derailed near the Spuyten Duyvil station in the Bronx, New York. The train's event recorder data indicated it was traveling at $82 \mathrm{mph}$ when it derailed at a curved area of track with a speed limit of $30 \mathrm{mph}$. The engineer was alone in a cab car at the front of the train and the locomotive was located at the rear of the train. All 7 passenger cars and the locomotive derailed. As a result, 4 passengers died on scene and 59 people, including the engineer, were transported to local hospitals with injuries.

The NTSB investigated all aspects of this accident including weather, signals, track conditions, personnel training, and the train's mechanical functioning. ${ }^{1}$

The engineer's work schedule and sleep patterns were reviewed as part of the investigation. The engineer had regularly worked an overnight shift, ending in the pre-dawn hours, for about 2 and one-half years, and had moved to an early morning shift 2 weeks before the accident. He was off work the Thursday and Friday before the accident, and had awakened about 9:30 AM Thursday morning, slept from midnight to 7:30 AM or 8:00 AM (7.5 to 8 hours) on Thursday night/Friday morning, napped twice for a total of about 1.5 hours during the day on Friday, and slept from 8:30 PM to $3: 30 \mathrm{AM}$ (7 hours) on Friday night/Saturday morning. He worked from 5:04 AM to 2:55 PM on Saturday, the day before the accident. The night before the accident, he reported he went to sleep at about 8:30 PM and arose at 3:30 AM on Sunday, December 1 (7 hours), to get to work by his start time of 5:04 AM. He reported he generally slept well. ${ }^{2}$
Mary Pat McKay, MD, MPH Chief Medical Officer

National Transportation Safety Board 490 L'Enfant Plaza SW

Washington, DC 20016

Mary.mckay@ntsb.gov 
In an interview soon after the accident, the engineer described himself as "dazed" or "mesmerized" around the time of the derailment and the investigation found that emergency braking had been initiated only after the train cars had begun to derail.

For the medical investigation, physicians from the NTSB and Federal Railroad Administration (FRA) evaluated the factual evidence regarding the engineer's medical conditions and treatments and developed a factual report. ${ }^{3}$ The records included occupational medical records from Metro-North, which included triennial evaluations beginning with a pre-employment exam in 1999. In these records, the engineer did not report any significant medical conditions and was noted only to have high cholesterol. These forms did not include any questions regarding sleep disorders other than insomnia.

Using authority granted in Title 49 of the Code of Federal Regulations, Section 831.9, medical records were obtained and reviewed. Records from multiple visits to the engineer's personal physician taking place from 2010 to 2014 were reviewed. The engineer had long-standing gastresophageal reflux disease and high cholesterol. In August 2011, his $\mathrm{HgbA}_{1 \mathrm{c}}$ was $6.1 \%$ and a note in his medical record stated "pre-diabetes." In November 2011, he visited his primary care office with a number of complaints including "fatigue." He was 5 feet 11 inches $(180 \mathrm{~cm})$ tall and at that time weighed 248 pounds $(112.5 \mathrm{~kg})\left(\mathrm{BMI}=34.5 \mathrm{~kg} / \mathrm{m}^{2}\right){ }^{4}$ His thyroid and testosterone hormone levels were checked and he was placed on topical testosterone. No evaluation regarding the engineer's sleep habits, snoring, or daytime sleepiness by his health care providers was recorded.

Following the accident, the engineer underwent a sleep evaluation and polysomnography. His Epworth Sleepiness Scale score was $12 .{ }^{5}$ His overall apnea/ hypopnea index (AHI) was 52.5 episodes/hour, it rose to 67.5 episodes/hour when supine. He was diagnosed with severe obstructive sleep apnea (OSA). Over the course of continuous positive airway pressure (CPAP) titration on the same night, the engineer's AHI dropped to 13.4 episodes/hour. The engineer reported his symptoms had substantially resolved after a month of regular CPAP use and his Epworth Sleepiness Scale score had dropped to 1 .

\section{The Probable Cause}

The NTSB determined the probable cause of this accident was the engineer's "noncompliance with the 30 -mph speed restriction because he had fallen asleep due to undiagnosed, severe, obstructive sleep apnea exacerbated by a recent circadian rhythm shift required by his work schedule."

\section{DISCUSSION}

The engineer had slept 7 or more hours during each of the 3 nights before the accident, indicating he did not have a significant new, acute sleep debt. Two weeks previously, however, he had experienced an approximate 12-hour shift in his usual work schedule from early evening to early morning start times. Adjusting from a night shift to a day shift usually takes several days and may cause more sleepiness than adjusting to the night shift. It is unclear if 2 weeks is long enough to completely readjust to the day shift, as studies have typically ended after 1 week. ${ }^{6}$ Although an individual's preferred time of day (morning or evening) can have some effects, individuals routinely awake during the day are entrained to outdoor daytime light and typically have circadian lows between $2 \mathrm{AM}$ and $6 \mathrm{AM}$. This accident occurred after this period and after the sun was up (at 7:19 AM) therefore, a circadian sleepiness effect is less likely. Although the engineer's fatigue arose from a combination of issues, it is likely that the chronic sleep debt associated with years of poor quality sleep caused by his undiagnosed, severe obstructive sleep apnea was the greatest contributor to his falling asleep while operating the train.

In addition to its association with cardiovascular, metabolic, and cognitive problems, symptomatic obstructive sleep apnea significantly increases the risk of motor vehicle crashes and other occupational injuries, ${ }^{7-9}$ and treatment with CPAP reduces that risk by $65 \%$ to $87 \% .^{10}$ Some estimate that as many as $10 \%$ to $25 \%$ of the US adult population may have OSA and the majority of them are undiagnosed and/ or untreated. ${ }^{11,12}$ Obstructive sleep apnea creates a demonstrable public safety hazard when it goes undiagnosed or untreated in transportation operators. Between 2000 and this accident in the Bronx in 2013, the NTSB cited fatigue or microsleep related to undiagnosed or inadequately treated sleep apnea in 10 other accidents and incidents it investigated (Table 1).

The engineer in this accident had multiple OSA risk factors including obesity (BMI ranged from 33.2 $\mathrm{kg} / \mathrm{m}^{2}$ to $38.2 \mathrm{~kg} / \mathrm{m}^{2}$ in his primary care records), male gender, snoring, complaints of fatigue, and excessive daytime sleepiness. ${ }^{13}$ There were multiple opportunities for his occupational or personal health care providers to have diagnosed and treated the OSA before the accident. The occupational evaluations, however, did not ask about related symptoms and, even when the engineer complained of fatigue, his personal health care providers did not obtain a sleep history or recommend further evaluation.

Before this accident in the Bronx, the NTSB had made 18 recommendations across the transportation modes addressing a variety of issues such as the need 
Table 1. NTSB Accidents Related to Sleep Apnea

\begin{tabular}{|c|c|c|c|c|c|}
\hline Accident Location & Year & Mode & Fatalities & Injuries & Brief Description \\
\hline Baltimore, MD & 2000 & Rail transit & 0 & 17 & A transit train ran into the end-of-track bumping post. \\
\hline Jackson, TN & 2000 & Highway & 1 & 1 & $\begin{array}{l}\text { A tractor trailer struck a state trooper vehicle in a work zone, then } \\
\text { crossed the median and struck a passenger vehicle. }\end{array}$ \\
\hline Clarkston, MI & 2001 & Rail & 2 & 2 & $\begin{array}{l}\text { One freight train failed to stop at a signal and struck another } \\
\text { freight train head on. }\end{array}$ \\
\hline Memphis, TN & 2002 & Highway & 5 & 2 & A 15 -passenger child care van ran off the road. \\
\hline Hilo, HI & 2008 & Aviation & 0 & 0 & $\begin{array}{l}\text { Both flight crew on a Mesa Airlines commercial flight fell asleep } \\
\text { and overflew the destination airport. }\end{array}$ \\
\hline Newton, MA & 2008 & Rail transit & 1 & 8 & $\begin{array}{l}\text { A transit train passed a stop signal and rear ended a stopped } \\
\text { train, both loaded with passengers. }\end{array}$ \\
\hline Miami, OK & 2009 & Highway & 10 & 6 & $\begin{array}{l}\text { A tractor trailer ran into a queue of traffic, striking several pas- } \\
\text { senger vehicles. }\end{array}$ \\
\hline Port Arthur, TX & 2010 & Marine & 0 & 0 & $\begin{array}{l}\text { An oil tanker, the Eagle Otome, collided with } 2 \text { other ships; more } \\
\text { than } 460,000 \text { gallons of oil spilled into the waterway. }\end{array}$ \\
\hline Chaffee, MO & 2013 & Rail & 0 & 5 & $\begin{array}{l}\text { One freight train failed to stop at a signal and struck another } \\
\text { freight train, causing the collapse of a highway overpass. }\end{array}$ \\
\hline TOTAL & & & 21 & 41 & \\
\hline
\end{tabular}

to educate operators on sleep apnea signs, the need to screen operators for sleep apnea with specific questions about sleep and snoring, to evaluate the risk of sleep apnea by calculating BMI and measuring neck circumference, and about ensuring adequate treatment for OSA. ${ }^{14}$ Although commercial operators in all modes of transportation are required to undergo periodic medical examinations and meet specified health criteria, Federal Railroad Administration regulations require only hearing and vision testing during triennial health evaluations of railroad engineers and conductors. All other modes require a more comprehensive medical examination that includes history taking, a review of systems, vital sign measurement, a review of medications, and a complete physical examination. The NTSB has made a series of recommendations to the FRA regarding the need for a comprehensive medical certification program for railroad employees in positions where impairment in physical or cognitive functioning by medical conditions, including sleep apnea, or their treatment might create a safety hazard for the public. The status of that recommendation is currently "open, unacceptable response" because the FRA has not provided any plan of action for the development of such a system.

Regarding occupational medical evaluations for sleep disorders, currently, merchant mariners and commercial drivers are asked about sleep, snoring, and daytime sleepiness; only merchant mariners' medical examiners are asked to formally calculate and report BMI. ${ }^{15,16}$ Aviation medical examiners are instructed to screen pilots for OSA based on discussed symptoms and risk factors and request additional testing as indicated. ${ }^{17}$

Obstructive sleep apnea has effective treatments that decrease fatigue and crash risk. Once OSA is diagnosed, operators in marine, highway, and aviation modes are required to prove ongoing, routine use of the prescribed treatment to maintain a medical certificate. If treated with CPAP or bi-level positive airway pressure (BiPAP), the recommendation in highway mode is the "minimum acceptable average use of CPAP is 4 hours within a 24 -hour period, ${ }^{\prime 18}$ and pilots must demonstrate use during " $75 \%$ of sleep periods with an average minimum of 6 hours use per sleep period."16 Merchant mariners must have their CPAP/BiPAP use reviewed by the US Coast Guard medical team but no specific criteria for a medical certificate are currently published.

In contrast, the FRA does not require any evaluation for sleep disorders or other medical conditions, medications, or treatments that might affect the safe operation of a train. (Title 49 Code of Federal Regulation Section 240.121). In this case, Metro-North's evaluation, while not robust enough to identify OSA risk factors, was considerably more extensive than the minimum required in rail. Following its investigation, the NTSB recommended enhancements to Metro-North's occupational medical evaluations; these enhancements are underway. ${ }^{19}$

In addition to the occupational medicine evaluations required by regulation, the engineer in this case had a primary care provider he visited with some frequency and who knew of his occupation. The provider, however, did not make the diagnosis in this case-even though the engineer complained of fatigue and was evaluated for it. Unfortunately, that is not unique. In 2 recent studies, the majority of primary care physicians (a mix of family medicine and internal medicine physicians) did not consider a diagnosis of OSA or other sleep disorders and failed to ask relevant questions 
about sleepiness and snoring even when their patients reported related symptoms. ${ }^{20,21}$ The routine use of a validated sleep evaluation instrument such as the Epworth Sleepiness Scale or the Berlin, STOP, or Cleveland Sleep Habits questionnaires may improve the identification of patients with potential sleep disorders over primary care physician interview alone. ${ }^{22}$ As a result of this investigation, the NTSB recommended enhancements to physician education regarding obstructive sleep apnea to both the American Academy of Family Physicians and the American College of Physicians.

While it is important for the health of an individual patient to include obstructive sleep apnea in the differential diagnosis of fatigue or sleepiness, the outcome in this case highlights the importance of increased vigilance when the patient works in a position where impairment of physical or cognitive function or sudden incapacitation could result in devastating harm to the public.

\section{CONCLUSION}

In this case, the federally regulated railroad occupational medicine system, the Metro-North medical system, and the engineer's primary care providers did not diagnose and ensure adequate treatment of his obstructive sleep apnea before the derailment. As a result, there were 4 deaths and 59 injured survivors. Preventing the next sleep apnea-related accident requires ongoing attentiveness throughout the medical care system to ensure transportation operators are screened, evaluated, diagnosed, and effectively treated for this condition.

To read or post commentaries in response to this article, see it online at http://www.annfammed.org/content/13/6/583.

Key words: railroads; accidents; sleep apnea syndromes; diagnosis

Submitted May 29, 2015; submitted, revised, August 27, 2015; accepted August 31, 2015.

\section{References}

1. The National Transportation Safety Board. Railroad accident brief: Metro-North railroad derailment. http://www.ntsb.gov/investigations/ AccidentReports/Reports/RAB1412.pdf. Accessed Apr 15, 2015.

2. National Transportation Safety Board. Human performance factual report. http://dms.ntsb.gov/pubdms/search/document.cfm?doclD = 430978\&docketID=55841\&mkey=88495. Published Aug 20, 2015.

3. National Transportation Safety Board. Medical factual group chairman report. http://dms.ntsb.gov/pubdms/search/document.cfm?doclD $=410984$ \&docket $\mathrm{ID}=55841$ \&mkey=88495. Published Apr 4, 2014 .

4. US Department of Health and Human Services; National Heart Lung and Blood Institute. Calculate your body mass index. http:// www.nhlbi.nih.gov/health/educational/lose_wt/BMI/bmicalc.htm. Accessed May 6, 2015.
5. Johns MW. A new method for measuring daytime sleepiness: the Epworth sleepiness scale. Sleep. 1991;14(6):540-545.

6. Bjorvatn B, Stangenes $K$, Øyane $N$, et al. Subjective and objective measures of adaptation and readaptation to night work on an oil rig in the North Sea. Sleep. 2006;29(6):821-829.

7. Mulgrew AT, Nasvadi G, Butt A, et al. Risk and severity of motor vehicle crashes in patients with obstructive sleep apnoea/hypopnoea. Thorax. 2008;63(6):536-541.

8. Lindberg E, Carter N, Gislason T, Janson C. Role of snoring and daytime sleepiness in occupational accidents. Am J Respir Crit Care Med. 2001;164(11):2031-2035.

9. Basoglu OK, Tasbakan MS. Elevated risk of sleepiness-related motor vehicle accidents in patients with obstructive sleep apnea syndrome: a case-control study. Traffic Inj Prev. 2014;15(5):470-476.

10. Tregear S, Reston J, Schoelles K, Phillips B. Continuous positive airway pressure reduces risk of motor vehicle crash among drivers with obstructive sleep apnea: systematic review and meta-analysis. Sleep. 2010;33(10):1373-1380.

11. Peppard PE, Young T, Barnet JH, Palta M, Hagen EW, Hla KM. Increased prevalence of sleep-disordered breathing in adults. Am J Epidemiol. 2013;177(9):1006-1014.

12. Hiestand DM, Britz P, Goldman M, Phillips B. Prevalence of symptoms and risk of sleep apnea in the US population: results from the National Sleep Foundation sleep in America 2005 poll. Chest. 2006. 130(3):780-786.

13. Young T, Shahar E, Nieto FJ, et al.; Sleep Heart Health Study Research Group. Predictors of sleep-disordered breathing in community-dwelling adults: the Sleep Heart Health Study. Arch Intern Med. 2002;162(8):893-900.

14. National Transportation Safety Board. Safety recommendations. http://www.ntsb.gov/safety/safety-recs/_layouts/ntsb.recsearch/ RecTabs.aspx.

15. Federal Motor Carrier Safety Administration. Medical examination report for commercial driver fitness determination. http://www.fmcsa. dot.gov/sites/fmcsa.dot.gov/files/docs/Medical_Examination_Report_ for_Commercial_Driver_Fitness_Determination_649-F\%286045\%29. pdf. Accessed May 5, 2015.

16. United States Coast Guard. Merchant Mariner credential medical evaluation report. http://www.uscg. mil/forms/cg/cg_719k.pdf. Accessed May 3,2015.

17. Federal Aviation Administration. 2015 Guide for aviation medical examiners. http://www.faa.gov/about/office_org/headquarters_ offices/avs/offices/aam/ame/guidel. Accessed May 1, 2015.

18. Hartenbaum N, Collop N, Rosen IM, et al. Sleep apnea and commercial motor vehicle operators: statement from the joint task force of the American College of Chest Physicians, American College of Occupational and Environmental Medicine, and the National Sleep Foundation. JOEM. 2006;48(9):S1-S3.

19. National Transportation Safety Board. Safety recommendation R-14064. http://www.ntsb.gov/safety/safety-recs/_layouts/ntsb.recsearch/ Recommendation.aspx?Rec=R-14-064. Published Nov 24, 2014.

20. Mold JW, Quattlebaum C, Schinnerer E, Boeckman L, Orr W, Hollabaugh K. Identification by primary care clinicians of patients with obstructive sleep apnea: a practice-based research network (PBRN) study. J Am Board Fam Med. 2011;24(2):138-145.

21. Grover M, Mookadam M, Armas D, et al. Identifying patients at risk for obstructive sleep apnea in a primary care practice. J Am Board Fam Med. 2011;24(2):152-160.

22. Senthilvel E, Auckley D, Dasarathy J. Evaluation of Sleep Disorders in the Primary Care Setting: History Taking Compared to Questionnaires. J Clin Sleep Med. 2011;7(1):41-48. 